\title{
Study on Interface Microstructure and Bonding Properties of Hot-Rolled Nickel-Based Composite Plate
}

\author{
Yunzan Ma $(\mathbb{D}$, Weijiang Yang, Qi Liu, Kejia Liu, and Kun Chen $(1)$ \\ School of Materials Science and Engineering, Shanghai Institute of Technology, Shanghai 201418, China \\ Correspondence should be addressed to Kun Chen; chk119@sit.edu.cn
}

Received 20 October 2021; Accepted 24 December 2021; Published 12 January 2022

Academic Editor: Laszlo Toth

Copyright ( $\odot 2022$ Yunzan Ma et al. This is an open access article distributed under the Creative Commons Attribution License, which permits unrestricted use, distribution, and reproduction in any medium, provided the original work is properly cited.

In this paper, the interface microstructure, elements' diffusion features at the interface, and bonding properties in nickel-based alloy/carbon steel clad composite prepared by vacuum hot-roll bonding were investigated, comprehensively. The influence of element distribution on the interface bonding strength was revealed as well. The results showed that there was a $13 \mu \mathrm{m}$ thick diffusion layer at the interface of nickel-based alloy/carbon steel composite plate, which was beneficial to a strong bond between nickel-based alloy and carbon steel, as well as the stable transition of mechanical properties in the thickness direction. Kirkendall voids and fine-grained structure (the grain size is about $41.5 \mathrm{~nm}$ ) were observable by peeling off the nickel-based alloy cladding, which greatly promoted element diffusion and enhanced the interfacial bonding strength of the nickel-based alloy/carbon steel composite plate. The diffusion coefficient of $\mathrm{Ni}$ at the interface was about 2 orders of magnitude larger than that of nanocrystalline Fe. The shear strength reached up to $453 \mathrm{MPa}$, which was much higher than the minimum of $140 \mathrm{MPa}$ defined in ASTM A-264 specifications. Furthermore, in the shear test, the fracture occurred on the X52 carbon steel side at the contact rather than at the composite plate interface.

\section{Introduction}

With the progress of science and technology in modern society in recent years, the fields, such as automobiles, ships, and industry, are increasingly demanding the comprehensive performance of materials, which makes a single material difficult to meet the requirements. Therefore, composites integrating the superior performance of various materials have become one of the important research directions [1-7]. One of the most widely used composite materials is nickelbased alloy composite plate prepared by hot-roll bonding, which not only holds high corrosion resistance from nickelbased alloy $[8,9]$ but also the structural support can be utilized from carbon steel or low alloy steel. In addition, the amount of nickel-based alloys can be reduced [10], which greatly reduces material costs and has a wide application prospect in the chemical industry, petroleum, seawater desalination, and other fields $[11,12]$.

In the composite material, interfacial delamination is one of the major problems, which takes great responsibility for the failure during its service [13-15]. Therefore, the interface bonding strength plays a decisive role in the overall mechanical properties and subsequent processing properties of composite materials [16]. The composite interface can affect the stress which transfers between the substrate and cladding metal, the crack growth, and the stability of the medium. Thus, the interface microstructure and the bonding strength determine the overall performance of the composite plate. Hence, it is of great significance to reveal the relationship between the interface microstructure and the bonding properties of composite plates [17, 18]. Recently, much research studies on the bonding mechanism, interface element diffusion, interface microstructure, and performance evaluation of rolled composite plates have been conducted, but most studies only give a qualitative explanation rather than quantitative analysis; such as [19-22]; research studies on the mechanical properties based on microstructure and element distribution, however, did not further reveal the mutual diffusion coefficient between interface elements and the evolution of the interface 
microstructure. Especially, this paper focuses on the mutual diffusion coefficient of elements, the scale structure characterization of the interface microstructure, and the shear fracture characteristics of NO8825-X52 nickel-based alloy composite plate. To calculate the mutual diffusion coefficient, mathematical fitting is carried out to study the major element distribution in the thickness direction of the composite plate. Furtherly, the interpretation of the mutual diffusion coefficient is presented from microstructure and grain size. Then, the relationship between interface microstructure and bonding strength discussed is based on the above quantitative studies. The purpose is to improve the comprehensive performance of composite materials through the control of interface microstructure, which provides a scientific and theoretical basis for the processing of nickelbased alloy composite plates.

\section{Materials and Methods}

The nickel-based alloy composite plate was prepared by vacuum hot-roll bonding. X52 carbon steel was chosen as the substrate with the thickness of $9 \mathrm{~mm}$ and NO8825 nickel-based alloy was chosen as the cladding with the thickness of $3 \mathrm{~mm}$. The chemical compositions of the metals are listed in Table 1.

The $10 \times 10 \times 12 \mathrm{~mm}$ metallographic specimens were cut in the thickness direction at the interface of the composite plate. Due to the difference of corrosion resistance between nickel-based alloy and carbon steel, the metallographic corrosion was conducted on nickel-based alloy and carbon steel separately. The carbon steel composite plate was etched with $4 \%$ nitric acid alcohol solution. The interface microstructure and element distribution of the specimens in the thickness direction were observed by optical microscope (OM), scanning electron microscope (SEM, Quanta 200 FEG, FEI), and energy dispersive spectrometer (EDS), respectively. The specimens were peeled off layer by layer from the nickel-based alloy side to the interface of the composite plate [23]. Ferric chloride hydrochloric acid solution was chosen as an etchant to make sure the peeling surface on the carbon side was freshly revealed during the mechanical peeling process. Then, after metallographic grinding and polishing, the microstructure of the peeling surface on the carbon steel side was observed and characterized by SEM and X-ray diffractometer (XRD, D/mas2000PC, Rigaku).

Figure 1 shows the shear specimens prepared according to the GB/T 6396-2008 standard [24]. The tensile shear tests were conducted by the electronic universal testing machine (Zwick/Roell, Z250, Germany) with a speed of $1 \mathrm{~mm} / \mathrm{min}$. The shear strength was calculated using equation (1), where $F$ is the applied load, $S$ is the area of the shear surface, and $S=4.5 \mathrm{~mm} \times 25 \mathrm{~mm}$ in the text, as shown in Figure 1:

$$
\tau=\frac{F}{S}
$$

The strain was monitored using an extensometer. The shear fracture microstructure and element content of the shear specimens were observed by SEM and EDS.
TABLE 1: Chemical composition of nickel-based alloy and carbon steel (wt. \%).

\begin{tabular}{lccccccc}
\hline Elements & $\mathrm{Ni}$ & $\mathrm{Cr}$ & $\mathrm{Mo}$ & $\mathrm{C}$ & $\mathrm{Mn}$ & $\mathrm{Si}$ & $\mathrm{Fe}$ \\
\hline 8825 & 38.000 & 19.500 & 2.500 & 0.025 & 1.000 & 0.500 & Balance \\
$\mathrm{X} 52$ & 0.012 & 0.021 & 0.004 & 0.100 & - & - & Balance \\
\hline
\end{tabular}

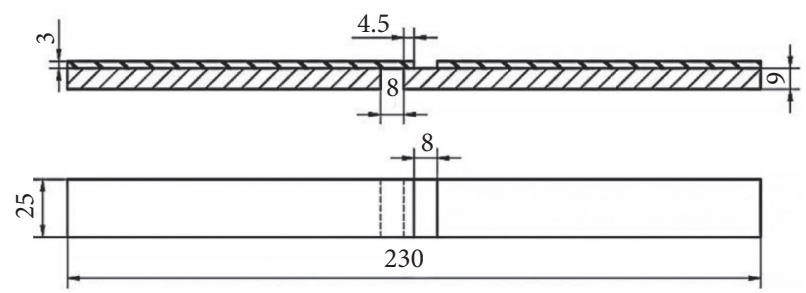

Figure 1: Schematic diagram of shear specimens (in $\mathrm{mm}$ ).

\section{Results and Discussion}

3.1. Morphologies at the Interface of Composite Plate. To investigate the microstructure of the transition zone, crosssection views are obtained and shown in Figures 2(a) and 2(b). It can be seen that the NO8825 nickel-based alloy is well combined with the carbon steel after hot-rolling processing, and the interface line is clear and straight, as well as the grain size at the interface of the carbon steel side decreases. Furthermore, at the X52 carbon steel side, a transition zone with a thickness of about $13 \mu \mathrm{m}$ near the interface can be observed. An enlarged picture is shown in Figure 2(c). The transition zone consisted of ferrite precipitation with short rod-like grains, which proved the diffusion of carbon components, similar to [25]. Figure 2(d) shows the line scanning element distribution along the thickness direction near the interface of the composite plate. The element contents of $\mathrm{Ni}, \mathrm{Cr}$, and $\mathrm{Fe}$ in the nickel-based alloy and carbon steel sides far away from the interface are unchanged. In the transition zone of the diffusion layer, the content of $\mathrm{Cr}$ and $\mathrm{Ni}$ elements decreases from the nickel-based alloy side to the carbon steel side, whereas the content of the Fe element increases. It indicates that a metallurgical bonding has been formed between nickel-based alloy and carbon steel. The elements of mutual diffusion take great responsibility for this. At high temperature, mutual diffusion through the bonding interface occurred, which induces the migration of the grain boundary and extends the bonding surface and thus forms a diffusion layer with a certain thickness at the interface [26-28].

\subsection{Element Diffusion at the Interface of the Composite} Plate. The mutual diffusion of these major elements will directly affect the bonding properties of the hot-roll bonding plate [29, 30]. Therefore, a fitting analysis of $\mathrm{Ni}$ and $\mathrm{Fe}$ distribution at the interface is conducted, which is shown in Figure 3. According to Fick's second law, the content of $\mathrm{Ni}$ and Fe distribution can be described by the error function. The solutions of the error function for the content of $\mathrm{Ni}$ and Fe distribution are as equation (2), respectively: 


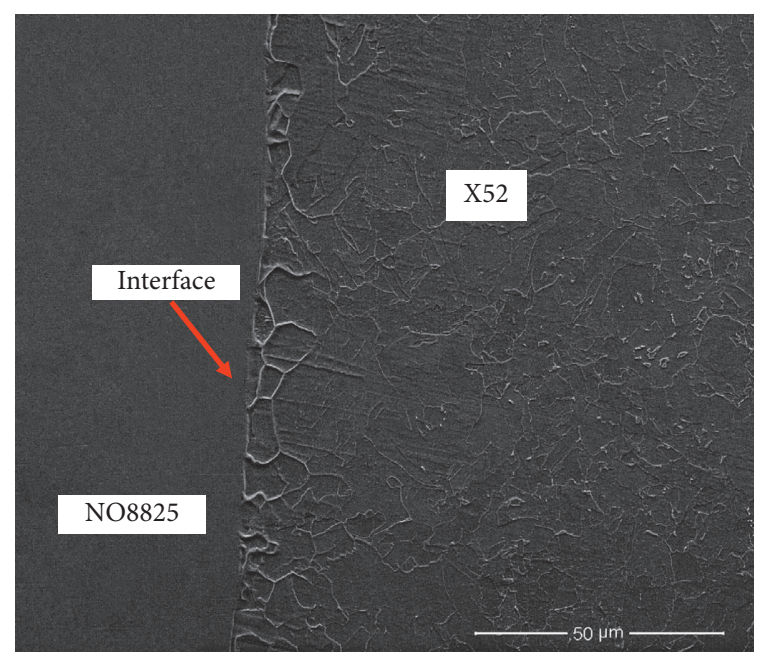

(a)

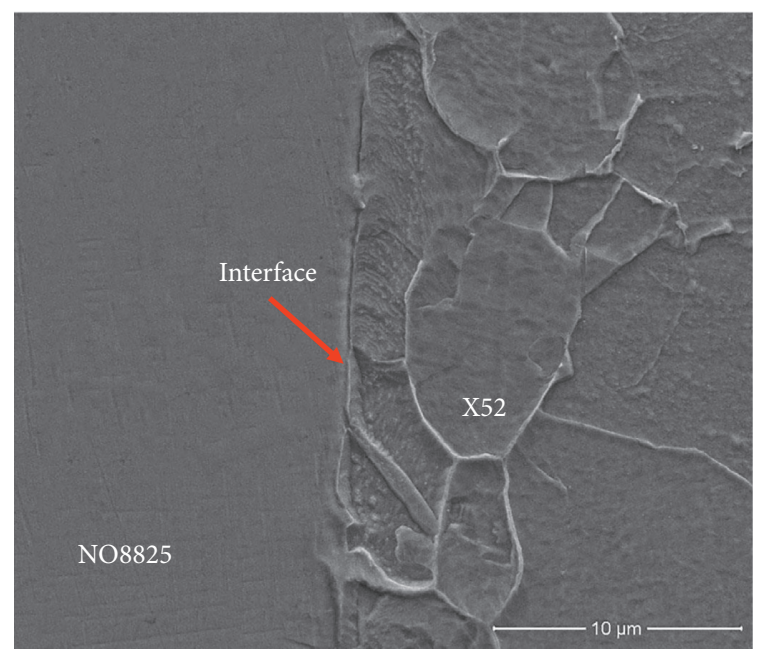

(c)

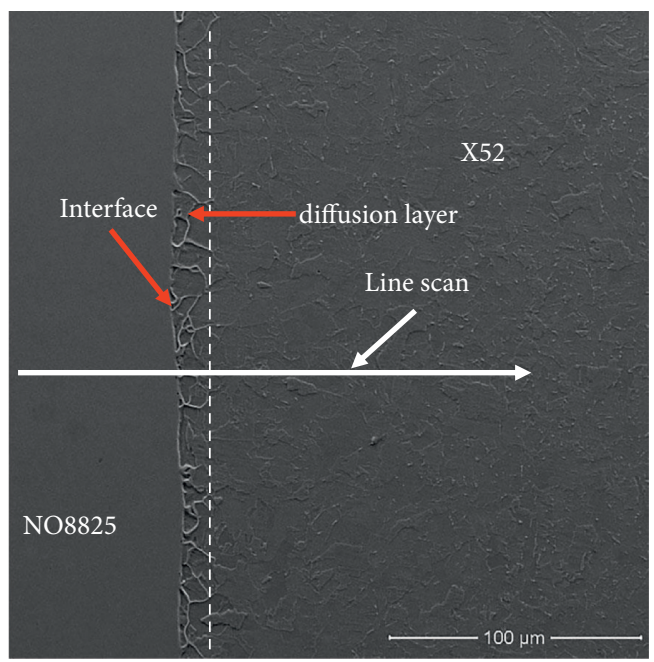

(b)

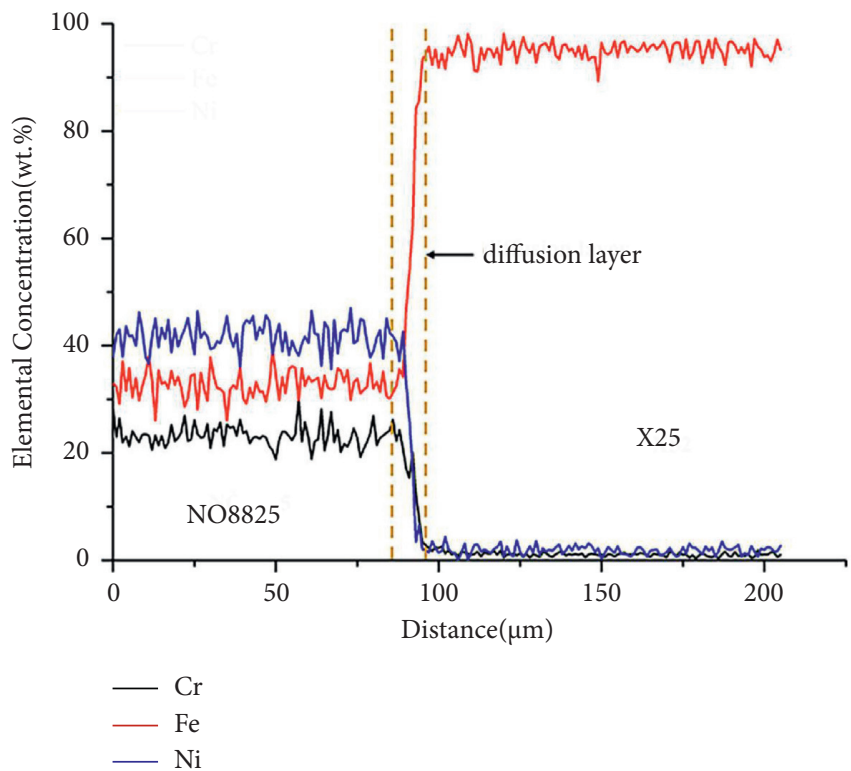

(d)

FIGURE 2: Morphologies at the interface of NO8825/X52 composite plate: (a) enlarged view of the X52 carbon steel side, (b) the cross-section morphologies of nickel-based alloy composite plate, (c) enlarged view of the transition zone, and (d) the EDS line of nickel-based alloy composite plate.

$$
\begin{aligned}
& \rho=22-20 \times \operatorname{erf}\left(\frac{x-91.5}{2 \sqrt{D_{\mathrm{Ni}} \times t}}\right), \\
& \rho=64+31 \times \operatorname{erf}\left(\frac{x-92}{2 \sqrt{D_{\mathrm{Fe}} \times t}}\right),
\end{aligned}
$$

where $t=1 \mathrm{~h}$.

Thus, the diffusion coefficients of elements $\mathrm{Ni}$ and $\mathrm{Fe}$ at the interface can be obtained as follows:

$$
\begin{aligned}
& D_{\mathrm{Ni}}=1.02 \times 10^{-13} \mathrm{~m}^{2} \cdot \mathrm{s}^{-1} \\
& D_{\mathrm{Fe}}=1.39 \times 10^{-13} \mathrm{~m}^{2} \cdot \mathrm{s}^{-1}
\end{aligned}
$$

Since the diffusion coefficient of the Fe element is greater than that of the Ni element, therefore, the Kirkendall voids formed in the carbon steel side of the composite plate.
According to [31], the diffusion coefficient of $\mathrm{Ni}$ in nanocrystalline $\mathrm{Fe}$ increases from $5.79 \times 10^{-15} \mathrm{~m}^{2} \cdot \mathrm{s}^{-1}$ to $8.48 \times 10^{-15} \mathrm{~m}^{2} \cdot \mathrm{s}^{-1}$ with the temperature rises from $650^{\circ} \mathrm{C}$ to $850^{\circ} \mathrm{C}$, which is about 2 orders of magnitude smaller than that in this work. This is likely due to the existence of the Kirkendall voids (see Figure 4), which greatly promoted the element's diffusion and contributed to the formation of metallurgical bonding with enhanced interfacial bonding strength $[32,33]$.

\subsection{SEM Morphologies and XRD Characterization of the Peeling Surface on the Carbon Steel Side}

3.3.1. Morphologies of the Peeling Surface on the Carbon Steel Side. To observe the transition zone of the diffusion layer in detail, the fresh revealed peeling surface on the carbon steel 


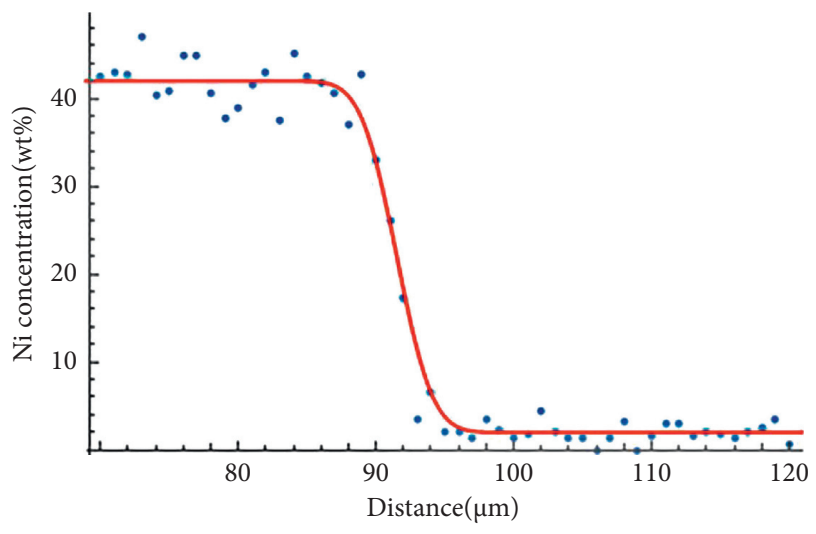

(a)

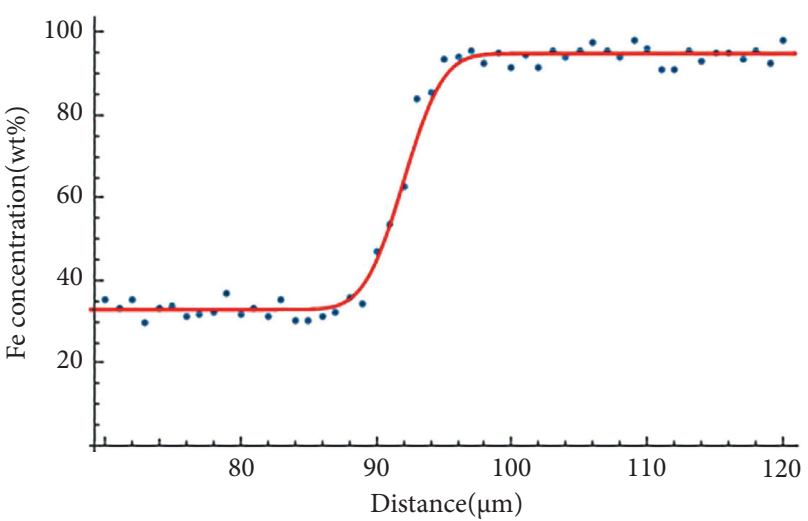

(b)

Figure 3: The content of $\mathrm{Ni}$ and Fe distribution at the interface and its fitting curve: (a) Ni and (b) Fe.
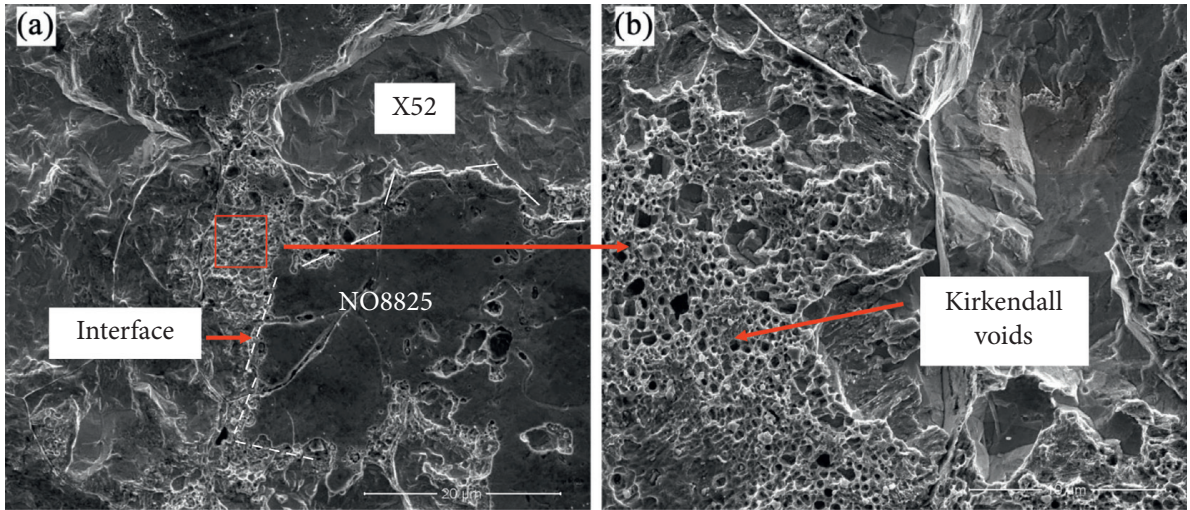

FIGURE 4: Morphologies of the fresh revealed peeling surface on the carbon steel side: (a) the fresh revealed peeling surface with less nickelbased alloy and (b) enlarged view of the red line marked area in Figure 4(a).

side with less nickel-based alloy was explored. Figure 4(a) shows that an obvious porous structure in the transition zone between nickel-based alloy (austenite phase) and carbon steel is observable. Figure 4(b) illustrates the enlarged view of the porous structure of the red line marked area in Figure 4(a). According to [34, 35], the Kirkendall effect is effective to interpret the results. Due to the existence of the Kirkendall voids, the fast channel for the element diffusion is provided, which promotes the element diffusion. It is under the $\mathrm{Ni} / \mathrm{Fe}$ element diffusion fitting calculation results obtained above.

3.3.2. XRD Characterization of the Peeling Surface on the Carbon Steel Side. To reveal the interface microstructure, XRD characterization was performed on the fresh revealed peeling surface with less nickel-based alloy (as shown in Figure 4) and the carbon steel substrate side, respectively. Electrolytic polishing was conducted on the carbon steel substrate side before XRD analysis. The XRD results obtained are shown in Figure 5, which reveals the broadening of the full width at half maximum (FWHM) of the (110) and (200) peaks when the peeling surface on the carbon steel side is fresh revealed. Table 2 shows the statistical results of FWHM of the (110) and (200) peaks.
To evaluate the average crystallite size, the Scherrer formula is applied here, which can be express as below [36]:

$$
D=\frac{0.89 \lambda}{\left(B-B_{0}\right) \operatorname{Cos} \theta},
$$

where $\lambda$ is the $\mathrm{X}$-ray wavelength, $\lambda=1.54 \AA$ in the text, $B_{0}$ is the instrument broadening factor, $B_{0}=0.091 \mathrm{deg}$ in the text, which needs to be converted into radian for calculation, $B$ is the full width at half maximum (FWHM), $\theta$ is the diffraction angle, and $D$ is crystallite size.

According to equation (3), the larger the FWHM is, the smaller the average crystallite size is. The calculated data are summarized in Table 2 . It is shown that the average crystallite size of the fresh revealed peeling surface and electrolytic polishing X52 substrate is $41.5 \mathrm{~nm}$ and $113.0 \mathrm{~nm}$, respectively. Crystallite size in the microstructure zone at the fresh revealed peeling surface is about 3 times finer than that of electrolytic polishing X52 substrate, which indicates the elemental transition zone has a fine-grained structure and strengthens the mechanical properties of the interface.

\subsection{Analysis of Shear Strength and Fracture of Composite} Plate. To explore the bonding strength of the composite, the stress-strain curve is obtained by the shear test, which is 


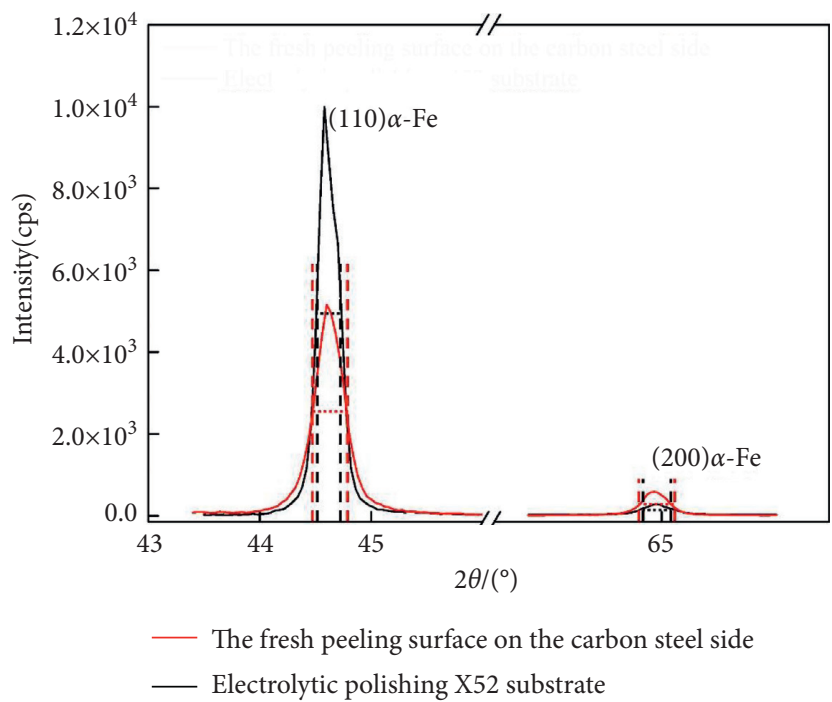

FIGURE 5: XRD patterns of electrolytic polishing X52 substrate and the fresh peeling surface on the carbon steel side.

TABLE 2: FWHM of fresh revealed peeling surface on the carbon steel side and electrolytic polishing X52 substrate.

\begin{tabular}{|c|c|c|c|c|}
\hline Samples & $2 \theta /^{\circ}$ & $(\mathrm{h} \mathrm{k} \mathrm{l)}$ & $\mathrm{FWHM} /{ }^{\circ}$ & Average crystallite size $(\mathrm{nm})$ \\
\hline \multirow{2}{*}{ The fresh revealed peeling surface on the carbon steel side } & 44.593 & 110 & 0.263 & \multirow{2}{*}{41.5} \\
\hline & 64.855 & 200 & 0.369 & \\
\hline \multirow{2}{*}{ Electrolytic polishing X52 substrate } & 44.575 & 110 & 0.147 & \multirow{2}{*}{113} \\
\hline & 64.876 & 200 & 0.216 & \\
\hline
\end{tabular}

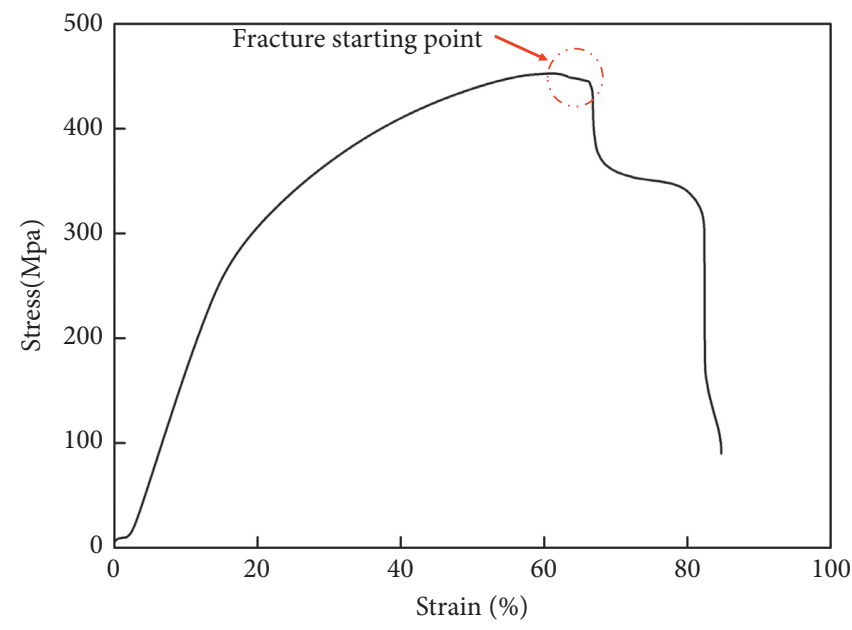

FIGURE 6: Stress-strain curve of composite plate shear test.

TABLE 3: The interface shear strength reported in [38-40].

\begin{tabular}{lcc}
\hline Shear strength $(\mathrm{MPa})$ & Reference & Method \\
\hline 395 & {$[37]$} & Vacuum hot rolling \\
$352 / 340$ & {$[38]$} & Asymmetrically hot rolled \\
$282 \pm 5$ & {$[39]$} & Hot-roll bonding \\
\hline
\end{tabular}

shown in Figure 6. According to the fracture starting point, the shear strength is $453 \mathrm{MPa}$, which is much higher than the minimum of $140 \mathrm{MPa}$ defined in ASTM A-264 specifications [37]. The bonding strength in this work is higher than the shear strength reported in [38-40], which is listed in Table 3. Furthermore, as can be seen from the sheer 


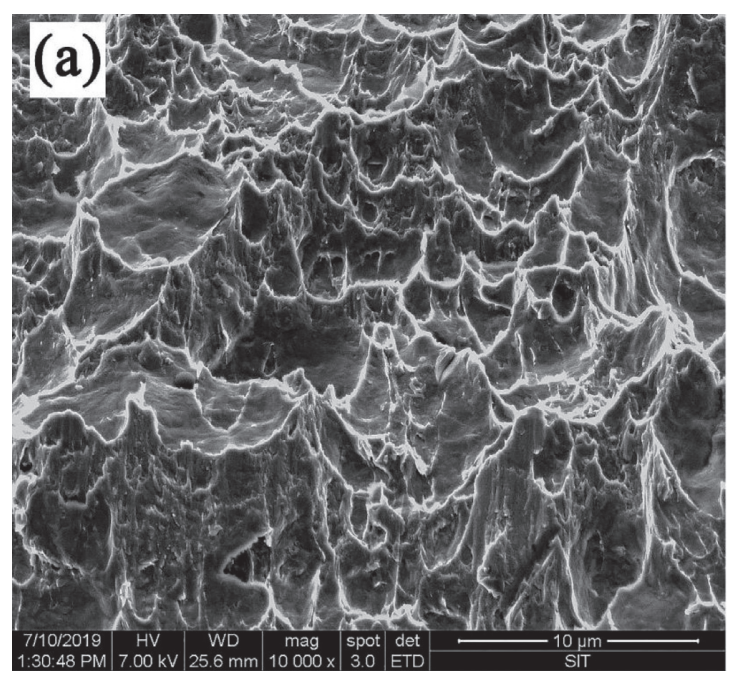

(a)

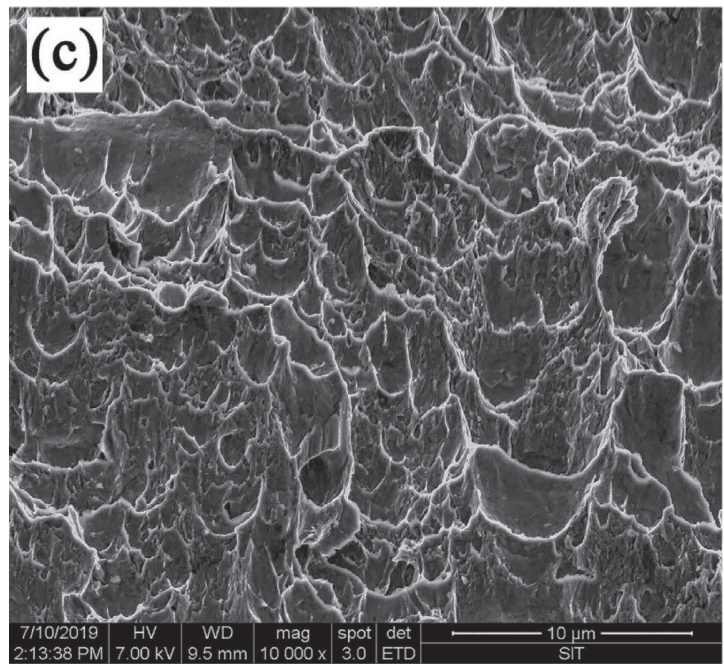

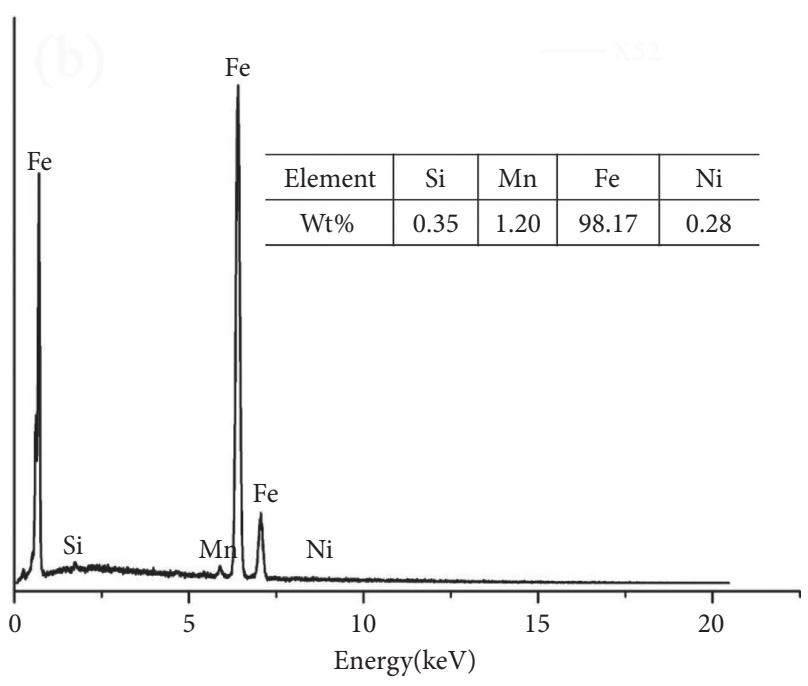

X52

(b)

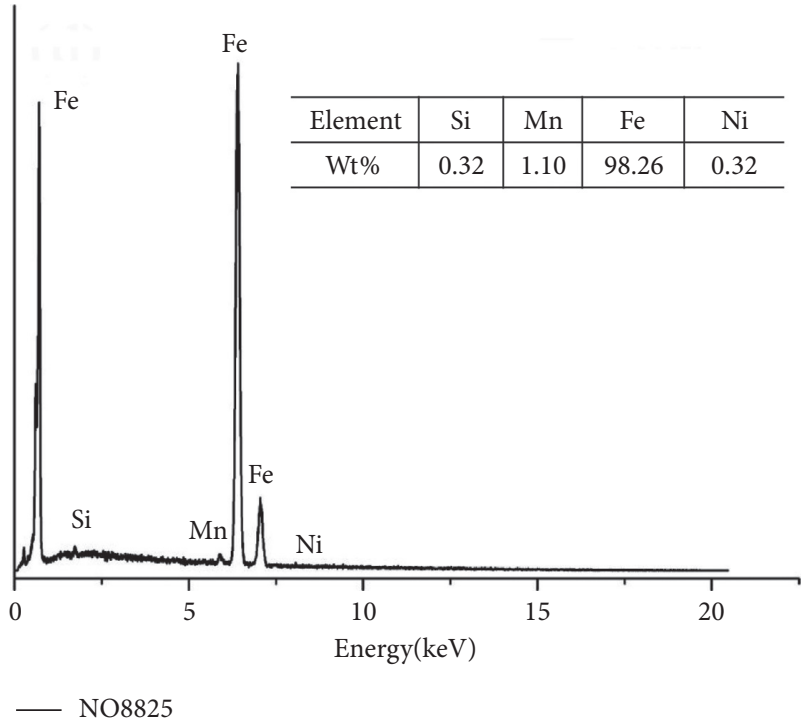

(d)

FiguRE 7: Microstructures of shear fracture and EDS on both sides of the shear sample: (a) fracture microstructure of the left side of the shear sample, (b) EDS of the left side of the shear sample, (c) fracture microstructure of the right side of the shear sample, and (d) EDS of the right side of the shear sample.

tensile curve, the stress increases with the strain rise until a sharp decrease at the fracture starting point, and then, the stress remains nearly constant until the shear sample is broken. It indicates that the transition zone of the element diffusion layer can effectively share the load and delay the deformation as an interface bonding zone between nickelbased alloy and carbon steel, avoiding the interface fracture.

Figures $7(\mathrm{a})$ and $7(\mathrm{c})$ are the shear fracture microstructure of both sides of the shear sample. It has obvious dimple characteristics and a ductile fracture has occurred, indicating that the nickel-based composite plate has good ductility and interfacial bonding strength. Furthermore, the EDS analysis of the shear fracture is shown in Figures 7(b) and 7(d). There is no Cr element, and there is almost no Ni element, but the content of the Fe element on the fracture surface is very high, which indicates that the fracture has occurred on the X52 carbon steel side near the interface rather than at the interface.

\section{Conclusions}

Based on the microstructure of the NO8825/X52 composite plate, there is a transition zone with a thickness of about $13 \mu \mathrm{m}$ at the interface. Due to the major element ( $\mathrm{Ni}, \mathrm{Cr}$, and $\mathrm{Fe}$ ) diffusion between nickel-based alloy and carbon steel, a $13 \mu \mathrm{m}$ thick diffusion layer is formed between nickel-based alloy and carbon steel. Furthermore, Kirkendall voids and fine-grained 
structure are revealed by peeling off the nickel-based alloy cladding, greatly promoting element diffusion, and improving the interfacial bonding strength of the NO8825/X52 composite plate. The diffusion coefficient of $\mathrm{Ni}$ at the interface is about 2 orders of magnitude larger than that of nanocrystalline $\mathrm{Fe}$, and the shear strength is much higher than the minimum of $140 \mathrm{MPa}$ defined in ASTM A264 specifications, as well as the fracture has occurred on the X52 carbon steel side near the interface rather than at the interface of the composite plate in the shear test. Thus, through the element transition zone of the diffusion layer, the mechanical properties at the interface of the composite plate achieve a stable transition from the nickelbased alloy side to the carbon steel side, which is beneficial to a strong bond between nickel-based alloy and carbon steel.

\section{Data Availability}

The data presented in this study are available from the corresponding author upon request.

\section{Conflicts of Interest}

The authors declare that they have no conflicts of interest.

\section{References}

[1] R. Rezaei, "Tensile mechanical characteristics and deformation mechanism of metal-graphene nanolayered composites," Computational Materials Science, vol. 151, pp. 181-188, 2018.

[2] L. Zhang, W. Wang, M. B. Shahzad, Y. Y. Shan, and K. Yang, "Fabrication and properties of novel multi-layered metal composites," Acta Metallurgica Sinica, vol. 56, no. 3, pp. 351-360, 2020.

[3] F. Daneshvar, M. Reihanian, and K. Gheisari, "Al-based magnetic composites produced by accumulative roll bonding (ARB)," Materials Science and Engineering: B, vol. 206, pp. 45-54, 2016.

[4] O. Bouaziz, J. P. Masse, G. Petitgand, and M. X. Huang, "A novel strong and ductile TWIP/martensite steel composite," Advanced Engineering Materials, vol. 18, no. 1, pp. 56-59, 2016.

[5] M. Naseri, M. Reihanian, and E. Borhani, "Bonding behavior during cold roll-cladding of tri-layered Al/brass/Al composite," Journal of Manufacturing Processes, vol. 24, pp. 125-137, 2016.

[6] H. Yu, C. Lu, A. K. Tieu, H. Li, A. Godbole, and C. Kong, "Annealing effect on microstructure and mechanical properties of Al/Ti/Al laminate sheets," Materials Science and Engineering: A, vol. 660, pp. 195-204, 2016.

[7] S. Tanhaei, K. Gheisari, and S. R. Alavi Zaree, "Effect of cold rolling on the microstructural, magnetic, mechanical, and corrosion properties of AISI 316L austenitic stainless steel," International Journal of Minerals, Metallurgy, and Materials, vol. 25, no. 6, pp. 630-640, 2018.

[8] A. A. Bogatov and D. R. Salikhyanov, "Development of bonding mechanisms for different materials during forming," Metallurgist, vol. 60, no. 11-12, pp. 1175-1179, 2017.

[9] M. Cetin, A. Gunen, M. Kalkandelen, and M. S. Karakas, "Microstructural, wear and corrosion characteristics of boronized AISI 904L superaustenitic stainless steel," Vacuum, vol. 187, p. 11, 2021.

[10] T.-W. Kim and C.-M. Lee, "Determination of the machining parameters of nickel-based alloys by high-power diode laser,"
International Journal of Precision Engineering and Manufacturing, vol. 16, no. 2, pp. 309-314, 2015.

[11] Z. Li, J. W. Zhao, F. H. Jia et al., "Interfacial characteristics and mechanical properties of duplex stainless steel bimetal composite by heat treatment," Mat Sci Eng a-Struct, vol. 787, p. $10,2020$.

[12] R. Cao, X. K. Zhao, Y. Ding et al., "Effects of the rolling temperature on microstructure and mechanical properties of 2Cr13/316L laminated composites prepared by accumulative roll-bonding (ARB)," Materials Characterization, vol. 139, pp. 153-164, 2018.

[13] M. Xiao, Z. Yongbo, W. Zhihua, and F. Huimin, "Tensile failure analysis and residual strength prediction of CFRP laminates with open hole," Composites Part B: Engineering, vol. 126, pp. 49-59, 2017.

[14] J. Jokinen and M. Kanerva, "Simulation of delamination growth at CFRP-tungsten aerospace laminates using VCCT and CZM modelling techniques," Applied Composite Materials, vol. 26, no. 3, pp. 709-721, 2019.

[15] Y. Cao, S. Y. Zhao, L. M. Sun, W. B. He, and J. Ma, "Experimental and simulated research on the ballistic performance of $\mathrm{Ti} / \mathrm{Al} 3 \mathrm{Ti}$ laminate composites," Advanced Composites Letters, vol. 29, p. 6, 2020.

[16] B. X. Liu, L. J. Huang, B. Kaveendran et al., "Tensile and bending behaviors and characteristics of laminated Ti-(TiBw/ Ti) composites with different interface status," Composites Part B: Engineering, vol. 108, pp. 377-385, 2017.

[17] Y. Y. Pang, G. Wu, H. T. Wang, D. Y. Gao, and P. Zhang, "Bond-slip model of the CFRP-steel interface with the CFRP delamination failure," Composite Structures, vol. 256, p. 13, 2021.

[18] S. Han, M. Sung, J. Jang, S. Y. Jeon, and W. R. Yu, “The effects of adhesion on the tensile strength of steel-polymer sandwich composites," Advanced Composite Materials, vol. 30, p. 19, 2020.

[19] D. R. Lesuer, C. K. Syn, O. D. Sherby, J. Wadsworth, J. J. Lewandowski, and W. H. Hunt, "Mechanical behaviour of laminated metal composites," International Materials Reviews, vol. 41, no. 5, pp. 169-197, 1996.

[20] A. Hosseini Monazzah, H. Pouraliakbar, R. Bagheri, and S. M. Seyed Reihani, "Al-Mg-Si/SiC laminated composites: fabrication, architectural characteristics, toughness, damage tolerance, fracture mechanisms," Composites Part B: Engineering, vol. 125, pp. 49-70, 2017.

[21] A. Eghlimi, M. Shamanian, M. Eskandarian, A. Zabolian, M. Nezakat, and J. A. Szpunar, "Evaluation of microstructure and texture across the welded interface of super duplex stainless steel and high strength low alloy steel," Surface and Coatings Technology, vol. 264, pp. 150-162, 2015.

[22] J. Xu, X. Gao, Z. Jiang, D. Wei, and S. Jiao, "Microstructure and hot deformation behaviour of high-carbon steel/lowcarbon steel bimetal prepared by centrifugal composite casting," International Journal of Advanced Manufacturing Technology, vol. 86, no. 1-4, pp. 817-827, 2016.

[23] R. Zhou, D. O. Northwood, and C. Liu, "On nitrogen diffusion during solution treatment in a high nitrogen austenitic stainless steel," Journal of Materials Research and Technology, vol. 9, no. 2, pp. 2331-2337, 2020.

[24] H. M. Hao, W. U. Zhi-Hong, S. J. Jia, L. I. Ba, and Q. Y. Liu, "Effect of annealing temperature on interface microstructure and properties of explosive welded N08825/X52 bimetallic plate," Transactions of Materials and Heat Treatment, vol. 37, no. 4, pp. 108-115, 2016. 
[25] K. Dong-Jin, L. Gyeong-Geun, K. Dae Jong, and J. Su, "Material characterization of $\mathrm{Ni}$ base alloy for very high temperature reactor," Journal of Materials Science \& Technology, vol. 12, no. v.29, pp. 76-82, 2013.

[26] J. Li, C. Liu, Y. Song, G. Zhao, L. Ma, and Q. Huang, "Influence of hot rolling + heat treatment on microstructure and mechanical properties of NM500/Q345/NM500 composite plate," Journal of Materials Science, vol. 56, no. 10, pp. 6016-6030, 2021.

[27] G. H. Zhao, Q. X. Huang, C. L. Zhou, Z. J. Zhang, L. F. Ma, and X. G. Wang, "Experiment and simulation analysis of roll-bonded Q235 steel plate," Revista de Metalurgia, vol. 52, no. 2, p. 9, 2016.

[28] J. Li, G. Zhao, Q. Huang, C. Zhou, Z. Zhang, and L. Ma, "Experimental and simulation analysis of the successful production of heavy-gauge steel plate by the clad rolling process," International Journal of Nonlinear Sciences and Numerical Stimulation, vol. 18, no. 5, pp. 403-409, 2017.

[29] X. Gao, Z. Jiang, D. Wei et al., "Effects of temperature and strain rate on microstructure and mechanical properties of high chromium cast iron/low carbon steel bimetal prepared by hot diffusion-compression bonding," Materials \& Design, vol. 63, pp. 650-657, 2014.

[30] Z. Li, J. W. Zhao, F. H. Jia et al., "Numerical and experimental investigation on the forming behaviour of stainless/carbon steel bimetal composite," International Journal of Advanced Manufacturing Technology, vol. 101, no. 1-4, pp. 1075-1083, 2019.

[31] J. C. Sun, "Diffusion of nickel in nanocrystalline iron," $\mathrm{Ma}$ terials Review, vol. 28, no. 2, pp. 159-162, 2014.

[32] B. X. Liu, S. Wang, W. Fang et al., "Microstructure and mechanical properties of hot rolled stainless steel clad plate by heat treatment," Materials Chemistry and Physics, vol. 216, pp. $460-467,2018$.

[33] B. X. Liu, Q. An, F. X. Yin, S. Wang, and C. X. Chen, "Interface formation and bonding mechanisms of hot-rolled stainless steel clad plate," Journal of Materials Science, vol. 54, no. 17, Article ID 11357, 2019.

[34] K. A. Dao, H. T. Pham, T. T. Nguyen, and A. T. Phan, "the formation mechanism and model of the surface nanoscale Kirkendall effect on $\mathrm{Au}$ catalyst island/GaAs substrate by thermal vapor-liquid-solid method with two-step temperature mode," Catalysts, vol. 9, no. 12, p. 15, 2019.

[35] J. M. Li, J. Jing, J. He, H. Chen, and H. B. Guo, "Microstructure evolution and elemental diffusion behavior near the interface of Cr2AlC and single crystal superalloy DD5 at elevated temperatures," Materials and Design, vol. 193, p. 10, 2020.

[36] K. Vaid, A. Chaurasia, S. Rawat, and U. K. Dwivedi, "Structural and dielectric properties of copper ferrite/LDPE composite," Materials Today Proceedings, vol. 43, no. 1, 2021.

[37] ASTM A264, Standard Specification for Stainless ChromiumNickel Steel-Clad Plate, ASTM International Standards organization, West Conshohocken, PA, USA, 2013.

[38] J. Jiang, H. Ding, Z.-A. Luo, and G.-M. Xie, "Interfacial microstructure and mechanical properties of stainless steel clad plate prepared by vacuum hot rolling," Journal of Iron and Steel Research International, vol. 25, no. 7, pp. 732-738, 2018.

[39] Z. Y. Chen, J. J. Qi, H. Q. Liu, L. Sun, and Z. Q. Tian, "Research on production technology of asymmetrically hot rolled stainless steel clad plate," Materials Science Forum, vol. 996, pp. 185-190, 2020.

[40] Z. Dhib, N. Guermazi, M. Gaspérini, and N. Haddar, "Cladding of low-carbon steel to austenitic stainless steel by hot-roll bonding: microstructure and mechanical properties before and after welding," Materials Science and Engineering: A, vol. 656, pp. 130-141, 2016. 